\title{
Optimization of Path of Mobile Robot BY GENETIC ALGORITHMS
}

\author{
VAupotic, B.; BREZOCNIK M.; FicKo M. \& BALIC, J.
}

Abstract: The paper deals with the optimization of the path of the mobile robot by genetic algorithms. The concept imitates the natural selection of living organisms, where in the struggle for natural resources the successful individuals gradually become more and more dominant, and adaptable to the environment in which they live, whereas the less successful ones are present in the next generations rarely. The responsibility of the mobile robot is to cover the shortest possible path from the starting point to the goal. The robot is self-learning and gathers the information from the environment by means of sensors. It processes the obtained information and then utilizes it for adopting its decisions. Throughout evolution it becomes more and more intelligent so that it manages to perform the set task.

Key words: Artificial Intelligence Methods, Evolutionary method, Genetic algorithms, Mobile robot, Path optimization
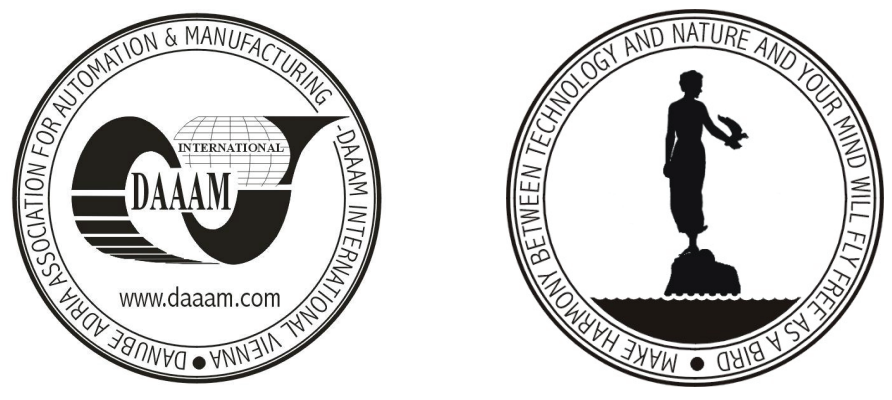

Authors' data: BSc. Vaupotic B.[ostjan], D.Sc. Brezocnik M.[iran], D.Sc. Ficko M.[irko], Prof. Balic J.[oze], Faculty for mechanical engineering Maribor, Slovenia, bostjan.vaupotic@uni-mb.si,mbrezocnik@uni-mb.si, Mirko.ficko@uni-mb.si

This Publication has to be referred as: Vaupotic, B.; Brezocnik M.; Ficko M. \& Balic, J. (2006). Optimization of Path of Mobile Robot by Genetic Algorithms, Chapter 50 in DAAAM International Scientific Book 2006, B. Katalinic (Ed.), Published by DAAAM International, ISBN 3-901509-47-X, ISSN 1726-9687, Vienna, Austria

DOI: 10.2507/daaam.scibook.2006.50 